\title{
Transition to Circular Economy. Solutions for an Intelligent City
}

\author{
Buhociu Dragos Horia \\ dragos buhociu@yahoo.com \\ Ion Mincu University of Architecture and Urbanism of Bucharest \\ Buhociu Florin Marian \\ florin.buhociu@,ugal.ro \\ Lazarescu Ioana \\ ioana.lupasc@,ugal.ro \\ Angheluta Laura-Delia \\ anghelutald@yahoo.ro \\ Dunarea de Jos University of Galati, Romania
}

\begin{abstract}
The European Union "produces" about three billion tons of waste each year and only a small part is leveraged on the rental, reuse or recovery markets. This model of production and consumption is dangerously testing the limits and global resources and poses serious threats to the sustainability and stability of our future. The consumer economic factor based on the phrase "produce-distribute-buy-use-throw", which implies the existence of large quantities of raw materials, cheap and easily accessible as well as cheap energy, will reach its physical limits of sustainability. In this context, we aim to analyze the concept of "circular economy" and to assume it as a viable alternative to smart cities. The results have shown that such a vision is a collaborative strategy that needs a bottom-up approach. Also, collaboration must be undertaken by all stakeholders within the intelligent city.
\end{abstract}

Keywords: circular economy, ecology, smart city, sustainable development, researchdevelopment-innovation

JEL Code: O3,Q5

\section{Introduction}

At European Union level, the Circular Economy (CE) implies minimizing waste and re-using and recycling existing materials and products. Moving to a circular economy will reduce environmental pressure, will increase security of raw material supply, will increase competitiveness, innovation and development, and will create new jobs.

Circular Economy is a component of Green Economy, being the one that ensures the efficient use of resources and waste management:

Fig.1 Green Economy and Circular Economy

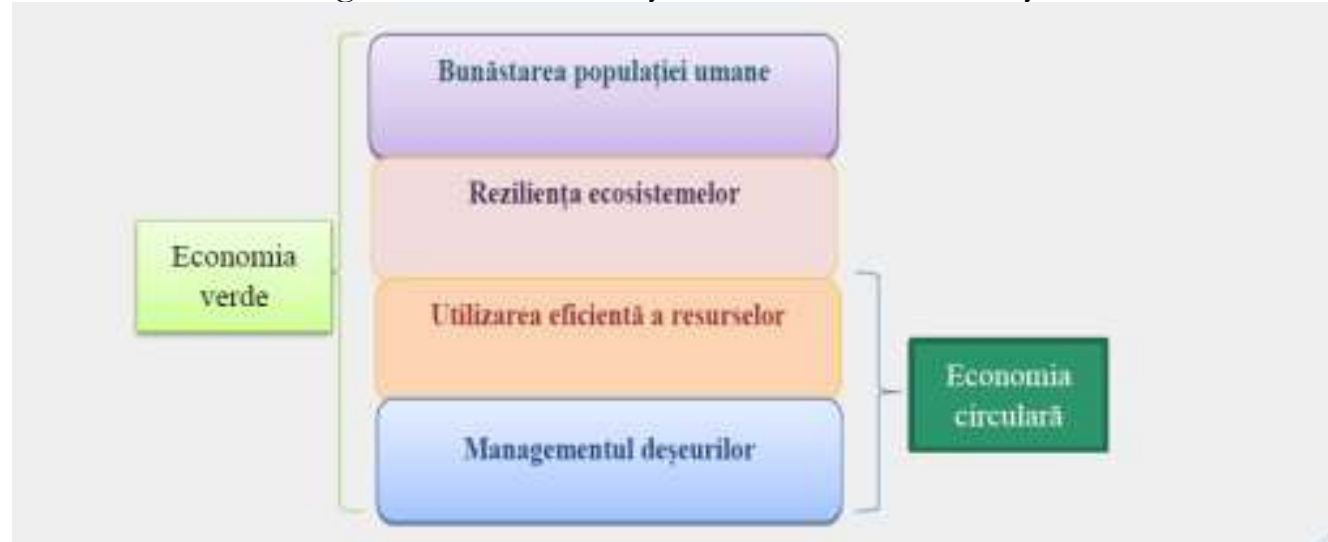

Source: Institutul European din Romania Studiu SPOS 2018, bttp:/ / www.ier.ro/ despre-noi.btml 
The circular economy tries to connect all flows of raw materials and materials by integrating them into a circular process that ensures efficient resource consumption and reduces to the maximum the resulted amount of waste.

Fig.2 Circular economy

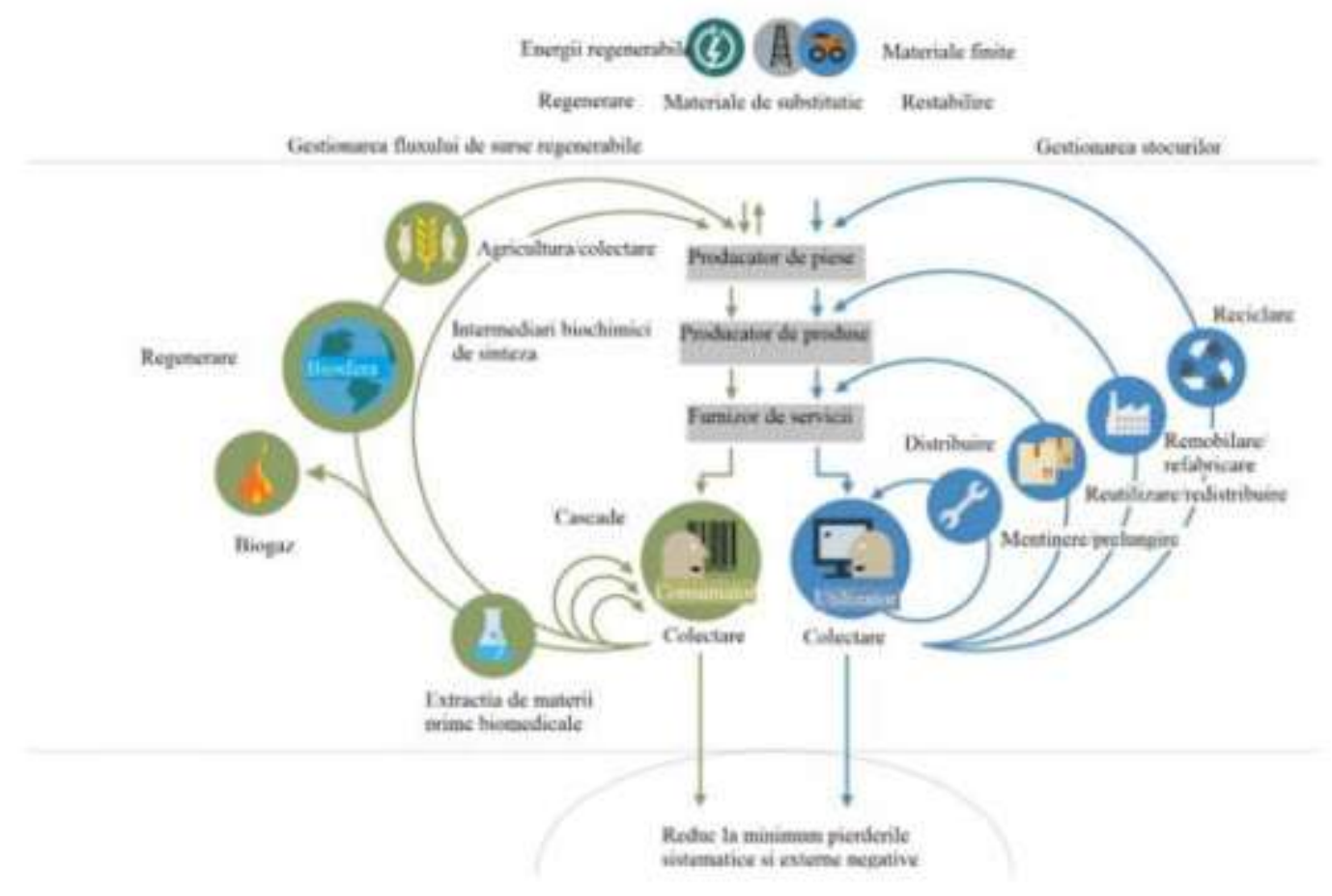

Source: https:/ / www.ellenmacarthurfoundation.org./ circular-economy/interactive-diagram

The main directions of sustainable development through the implementation of Circulation Economy principles:

\# closed loop recycling (waste is used as raw material in the production process),

\# dowcycling (recycling to produce products less than the value of processed waste),

\# upcycling (recycling through which products with a value greater than the value of processed waste are obtained),

\# industrial symbiosis (pooling of services or products across multiple industries to make resource use more efficient)

* selective collection of waste,

* product maintenance services,

* consumer loyalty (encouraging the repeated use of a sustainable product or service),

* modular design (designing a project to allow decomposition of the products into smaller parts so that they can be replaced individually when worn out)

personalizing sustainable products or services.

\section{Circular Economy Model and its Components}

Circular economy model consists of several components ranging from the raw materials that are part of a product, that is the design and production activities, followed by the distribution of the products / services provided/ rendered. The products thus obtained enter into industrial or domestic / individual consumption, and after a certain period of use they will be reused in other areas or repaired. What Circular economy model brings new is that products with some physical or moral wear go back into production processes, becoming raw materials for the industries concerned. Another part is collected as waste, following their specific path. 


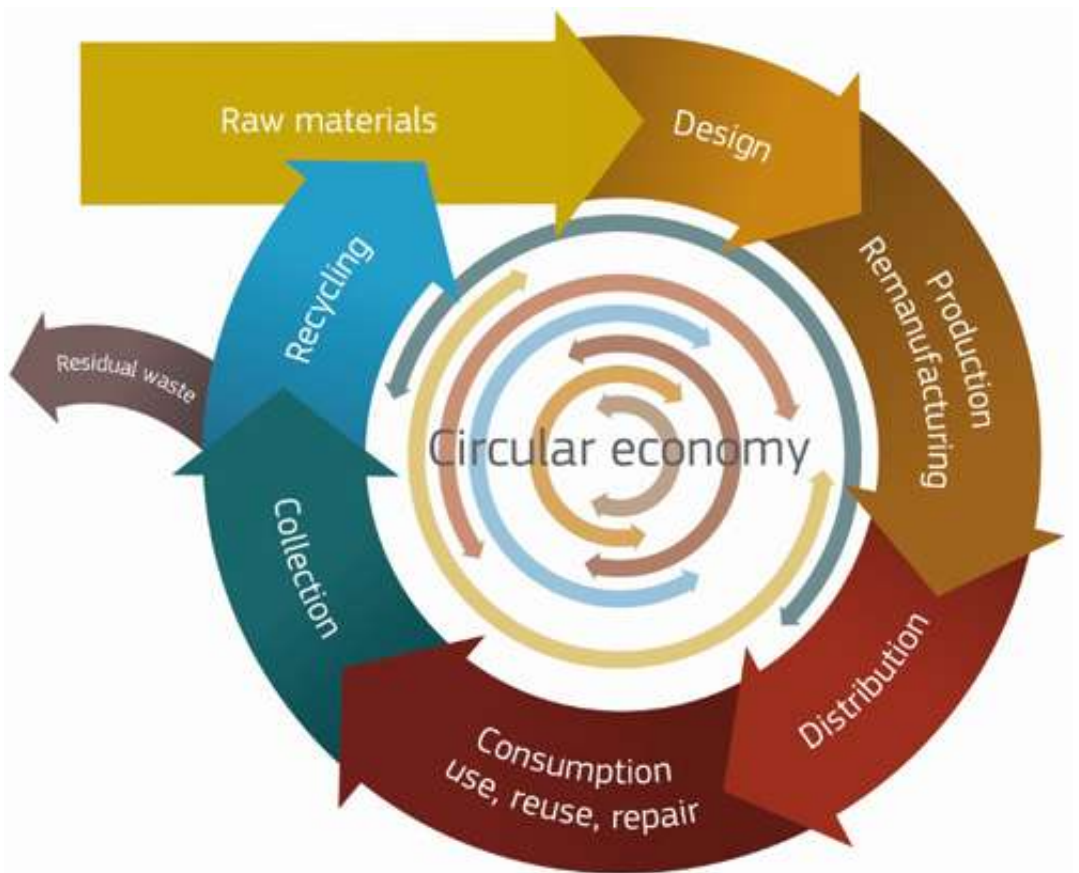

Source: bttps:// www.prwave.ro/ ce-este-economia-circulara-si-care-este-contextul-european/

The purpose of implementing the Circular economy principles is to reduce as much as possible the consumption of raw materials and energy fluids and on the other hand to ensure the full utilization of the products that are removed from the consumption for which they were produced.

According to UN forecasts, given that current trends of continued growth are maintained according to the linear model production-distribution-consumption-waste, the mankind will need resources of two Earths by 2030 and three Earths by 2050 to function in the current pace.

Fig.4 The environmental footprint of the world economy

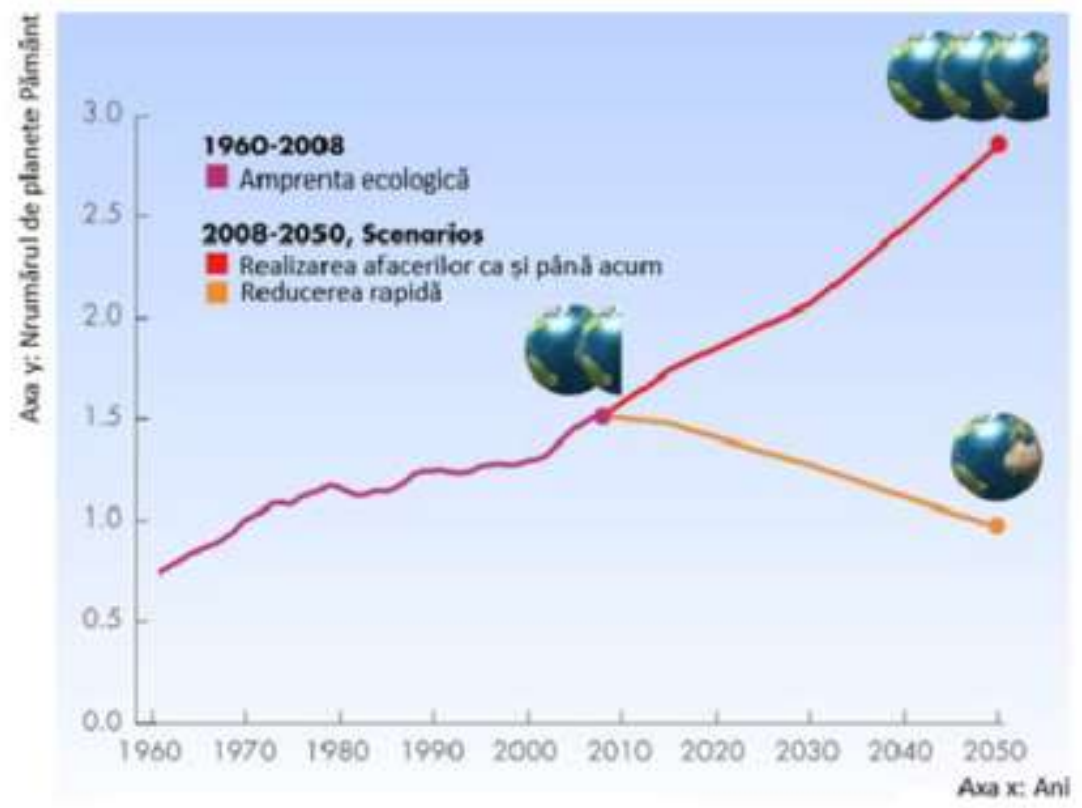

Source: Bonciu F.,Economia europeana: la un linear catre o economie circulara.Rom.J.Eur.Aff.vol. 14, nr. 4, 2014 


\section{Permanent circuits in Circular economy}

The specificity and advantages of EC application are given by the additional circuits:

- Reuse of products, which are used directly into the sales and distribution sector

- Repairing products, entering in the assembly sector

- Product restoration, entering in the production sector

Fig.5 Permanent circuits in Circular economy

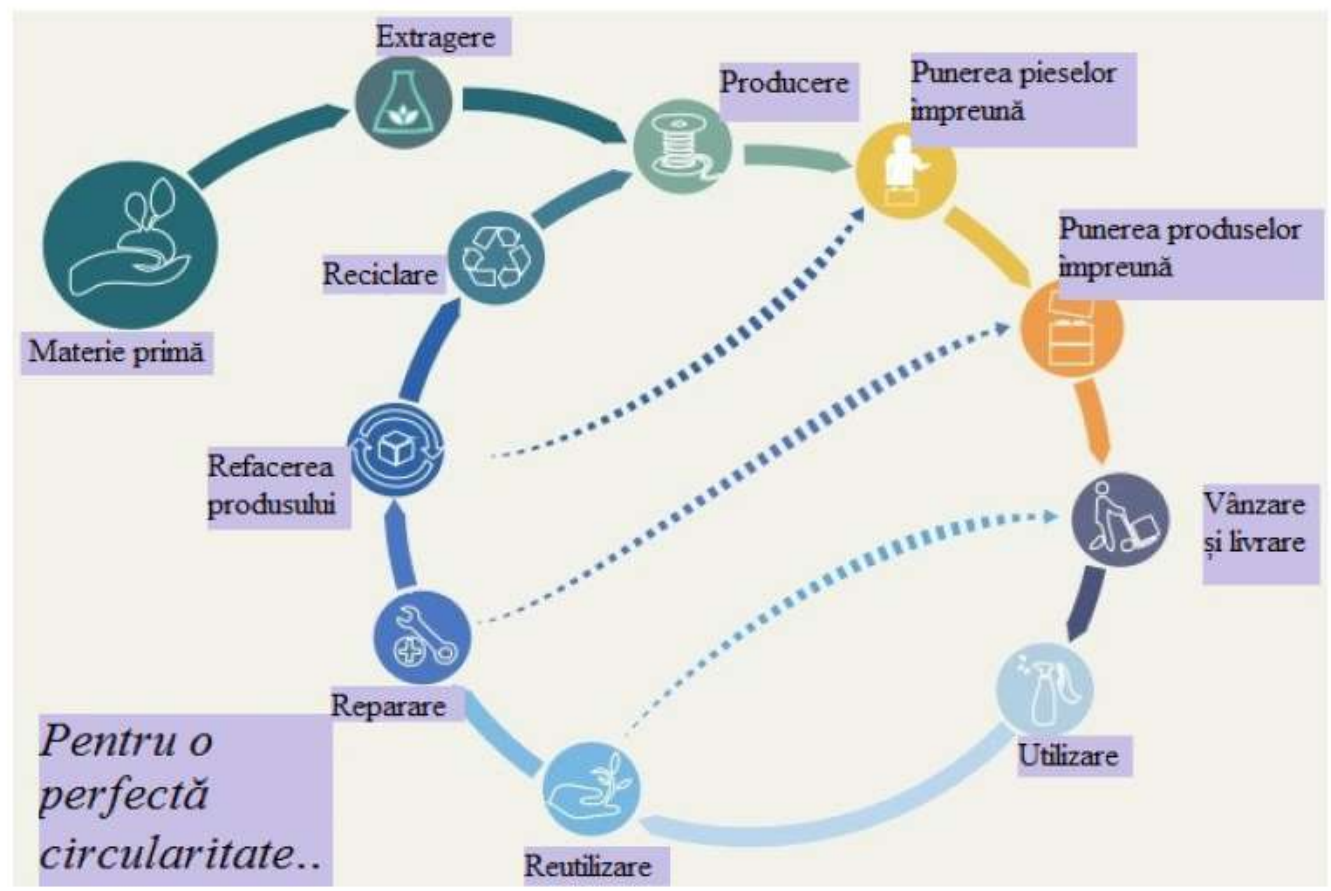

Source: Institutul European din Romania Studiu SPOS 2018, http://www.ier.ro/despre-noi.html

The main business models developed in the circular economy:

Circular suppliers - is significant in industries that need resources and rare raw materials; thus, these resources are replaced by 100\% renewable, recyclable or biodegradable materials.

Recovery of resources - is the one that ensures the elimination of material losses and maximizes the value of the product through returns to the raw material and material production system.

Extending product life - allows companies to extend the life of a product through repair, remanufacturing.

Sharing platforms - allow users to collaborate and share existing assets.

The product as a service - is a model that can replace the classic model "Buy - use - throw". Thus, one product can be used by one or more people, on the "rent and use" principle.

\section{Solutions for the smart city}

According to (1), in the national economy the Circular economy (CE) principles are known by sectors in the following percentages: 
Fig. 6 Level of knowledge of Circular economy (CE) principles by economic sectors

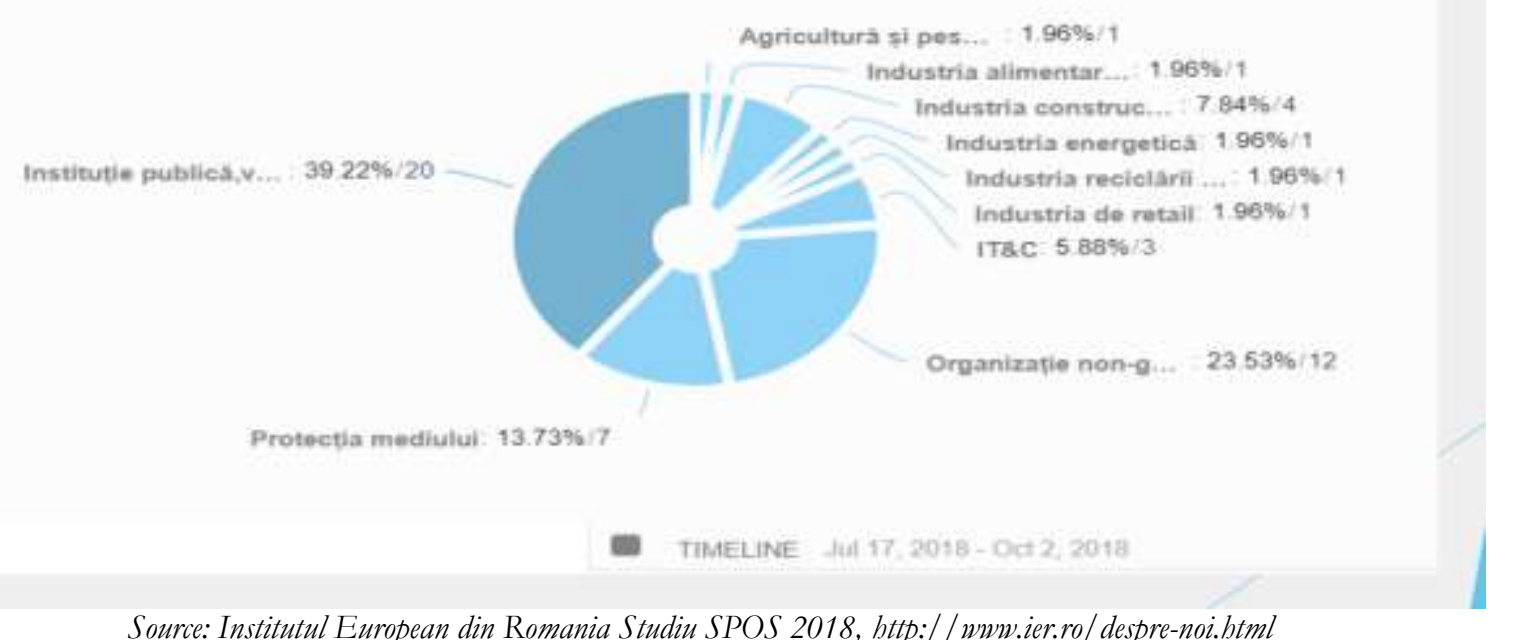

Source: Institutul European din Romania Studiu SPOS 2018, http:/ / www.ier.ro/ despre-noi.btml

It is noted that at the level of the public administration, represented by the specialized institutions, the degree of knowledge of Circular economy principles is best known compared to other sectors and fields of activity in the national economy.

Particularly important is the implementation of these principles at the level of urban localities which, on the one hand, represents the place where the main assets necessary for human activity are produced and supplied and, on the other hand, is the place where the largest amount of waste is generated. It is important to realize and implement those strategies based on the Circular economy principles, to allow the transition to the implementation of the characteristics of a "smart city".

Globalization, climate change, resource pressure, demographic change and the aging of the population are some of the main challenges faced by European cities. Addressing these issues, the EUROPA 2020 Strategy has set three key growth priorities:

- smart growth, to develop a knowledge and innovation economy;

- sustainable growth, promoting a greener, more competitive economy and managing resources more effectively;

- inclusive growth stimulating an economy which allows the creation of new jobs, ensuring a strong territorial and social cohesion [4].

According to the above mentioned strategy, urban regeneration plays a strategic role in urban development in Europe, with cities playing a key role in meeting its development goals [4].

The intelligent city concept has been around for 30 years, and it is constantly evolving over time, depending on the areas that have been included in it. Most interpretations of the intelligent city concept refer to the use of information and communication technology (ICT) to improve the quality of life in the city [5]. Intelligent cities are those that use renewable energy consumption sensors, web-hosted applications that can be installed on any mobile device, wireless networks, over-the-air digital surveillance, as well as automated data flow management and management systems public services, that is, those cities that use modern technology to improve the quality of life and to reduce the negative impact on the environment and thus reduce the high demand for energy [6],[7].

The most important directions in the development of smart cities are: -Life quality

-Sustainable development.

This means that they are aimed at serving their own citizens, be environmentally friendly, and help to use the Earth's resources as rationally as possible [6]. Due to the close link between the environment and the concept of intelligent cities, called "smart cities", it is concluded that the circular economy is a catalyst for the "urban intelligence" process. 
According to demographic experts, by $2020,80 \%$ of the population will live in the city, which means that the possibility to consider being a "smart" city turns into a real obligation to achieve as soon as possible.

It is therefore noticed that the circular economy, in the process of transition to smart cities, contributes by generating more value and innovation to help create more jobs and greater competitiveness.

Referring to holistic concepts such as "systems thinking", "urban metabolism" and "biomimicry," we appreciate that the way in which a sui generis city is operated does not differ much from that of a living organism. Such a holistic understanding succeeds in balancing material and energy exchanges between nature and society, leading to eco-efficiency and sustainable development. Cities have numerous resource flows that are not only of a material nature. Another dimension of flows, which in turn impose a certain level of public services such as education, transport, health, etc. Less waste can be produced in cities due to the cyclical economy This type of economy will represent a financial flows industry major projects that will also contribute to transforming cities into smart cities by generating new opportunities for new jobs.

Waste Management at Galati county

After investigating waste causes and storage in towns and villages of Galati county, there have been established the cities that will have municipal deposits, Galati and Tecuci, and, also, the areas where the waste will be collected from the rest of the county (Transfer Stations). In this way a unitary waste management will be ensured for the entire county.

Fig. 7 Waste recovery and recycling of Galati county

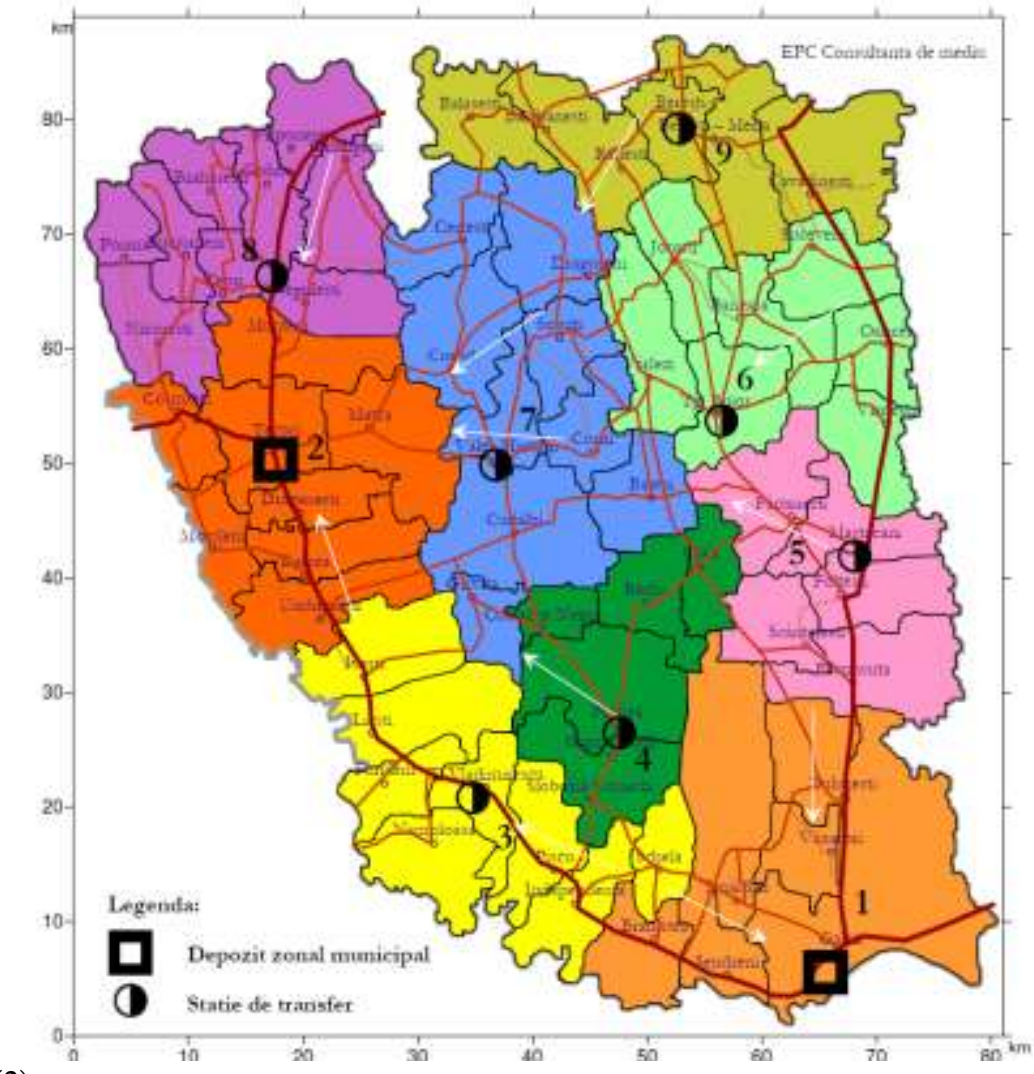

Source : (3) 


\section{Conclusions}

Several initiatives have been launched at European level to implement Circular economy EC principles:

- European Circular Economy Stakeholder Platform facilitates the exchange of information and best practices at European level

- European Cluster Collaboration Platform

- Enterprise Europe Network, designed to facilitate funding for eco-innovation, energy efficiency and resource use.

We can assume that the principles and methods of Circular economy EC implementation can lead to a superior capitalization of resources, in the conditions of reducing their consumption, but also to a superior valorization of industrial and domestic waste and thus to the foundation of the sustainable development of the national economy.

\section{References}

1. Institutul European din Romania Studiu SPOS 2018, http:/ / wnw.ier.ro/ despre-noi.btml

2. Bonciu F.,Economia europeana : la un linear catre o economie circulara.Rom.J.Eur.Aff.vol. 14, nr. 4, 2014

3. Plan Judetean de Gestionare a Deseurilor Judetul Galati wnw.epcmediu.ro, wnw.cjgalati.ro

4. bttp:// wnw.mdrt.ro/userfiles/declaratie_Toledo_ro.pdf

5. bttp:// en.smartiscity.eu/what-it-means-to-be-a-smart-city/,

6. bttps:// wnw.primariapn.ro/documents/87769/2006173/ghid_smart_city_ro.pdf

7. http:// wmw.inhabitat.ro/orasele-inteligente/

8. bttps:// wnw.ellenmacarthurfoundation.org./ circular-economy/interactive-diagram

9. bttps:// www.prwave.ro/ ce-este-economia-circulara-si-care-este-contextul-european/

10. Strategia EUROPA 2020 https:// eurlex.europa.eu/LexUriServ/LexUriServ.do?uri=COM:2010:2020:FIN:RO:HTML 